\title{
Model of a benefit/cost ratio analysis for comparison of environmental noise barriers
}

\author{
António P. O. Carvalho ${ }^{\mathrm{a}}$ \\ Pedro D. S. Oliveirab \\ Laboratory of Acoustics, FEUP - Faculty of Engineering \\ University of Porto, 4200-465 Porto \\ Portugal
}

The choice for an economically ideal solution of environmental noise barrier must acknowledge both the cost of its main components and the benefits it can provide, through time. An algorithm based on benefit/cost ratio (BCR) analysis was created to achieve a systematic analysis tool. It calculates the BCR for any potential noise barrier. The cost of a barrier can be described with known or quantifiable parameters such as barrier height, thickness, materials, initial investment costs, maintenance costs, replacement costs due to accidents, etc. The benefits associated with a solution are defined by computable parameters such as sound absorption, sound reduction, insertion loss, and even intangible parameters such as its visual impact and environmental impact. Each benefit is weighed regarding its importance. Using the necessary parameters it is possible to calculate the BCR of a barrier for any number of years of a life expectancy.

\section{INTRODUCTION}

The construction of environmental noise barriers servicing major transportation networks, such as highways and railways, is a highly expensive endeavor. With costs frequently reaching hundreds of Euros per square meter of barrier it is highly important to choose the best possible solution, that is, the one that provides the most benefits, not only in terms of acoustical characteristics but also in terms of environmental impact and aesthetics, while keeping costs, over time, at a minimum. Obviously when choosing which barrier is better suited for a specific location there are many parameters that need to be taken in consideration. A Benefit/Cost Ratio (BCR) analysis model is presented. It is based on the concept of the BCR method and it is applied to assist in the choice of the best environmental noise barrier solution. It accounts for different material characteristics, their costs and the benefits they provide.

\section{CONCEPT}

The developed model is based on the Engineering Economy concept of Benefit/Cost Ratio (BCR) (eq. 1 where, B: benefit; $\mathrm{C}$ : $\cos \mathrm{t} ; \mathrm{t}=0$ : present value; $n$ : life cycle, years) and is intended to assist in the comparison of environmental noise barriers. That concept would imply the definition

\footnotetext{
${ }^{a}$ Email address: carvalho@fe.up.pt

${ }^{\mathrm{b}}$ Email address: poliveira@fe.up.pt
} 
of benefits as a monetary value. As it is difficult to define some of the barrier's characteristics as a monetary value this model differs from the original economical concept of the BCR analysis although it is based on it.

$$
B C R=\frac{B}{C}(t=0)=\frac{\sum_{i=1}^{n} B_{i}(t=0)}{\sum_{i=0}^{n} C_{i}(t=0)}
$$

The benefits associated with each barrier (expressed in an abstract unit) are divided by the costs of that barrier (in a chosen monetary unit). The result is a non dimensional notion of relative value of the barrier that can be compared with other barriers.

In this document, a model of the BCR analysis method is presented and applied to environmental noise barriers. It also allows to analyze the BCR of each barrier for several time durations of the project's life cycle (the time a barrier is intended for use). This should not be confused with each barrier's life-cycle as this is associated with its own durability.

Every cost associated with a barrier is defined as present value (that is, for $t=0$ ). It is also assumed that every cost is known in its current value (even the ones that only occur in the future). Therefore no costs are affected by interest rates or inflation.

It is assumed that benefits remain constant through time whereas total costs increase. This allows to understand that for each value of the project's life cycle the same solution will have a different BCR. Thus it can be assumed that the best solution for a 20 year project (the barrier with the best BCR at that year) will not necessarily be the best solution for a 40 year project, for example. This model relates the quality of each solution with the time it is intended for use (project's life cycle).

\section{BASE VARIABLES}

Base variables encompass specific details of each barrier such as geometric data and its constitution, as well as some information about the surrounding environment.

Geometric data (barrier height, thickness, etc.) must be defined. Information on the surroundings must also be included. If the neighboring environment throughout the barrier's length is primarily composed of buildings and other similar structures it is considered as an "urban" environment. If the surrounding environment is free of buildings and other structures it is considered as a "non urban" environment. Depending on the characteristics of the environment the benefits of each barrier will be different as they are dependent of the surrounding environment.

Visual characterization of the barrier, in both of its sides, is also required. Which materials and how much of them compose each surface of the barrier must be known, through percentages. Information about color must also be included. Three main color classes were defined: Light (white concrete, acrylic sheets and similar tones), Medium (encompassing the main colors used, such as red, green, blue, gray, etc. and in concrete, brick and metallic barriers) and Dark (dark timber and similar colors such as black, deep blue, dark brown, etc.).

Additional information can also be included such as the existence of vegetation in front of the barrier or the use of recycled materials. These parameters must be defined separately for each side of the barrier allowing for situations where each side of the barrier has different characteristics. 


\section{COSTS}

\subsection{Concept}

The unitary cost of a barrier (that is, the cost per square meter) accumulated until year $n\left(\mathrm{C}_{n}\right)$ is expressed with eq. 2 (where $n$ is the number of years since the construction of the barrier, project's life cycle). It is the sum of preparatory costs $\left(\mathrm{C}_{\mathrm{P}}\right)$ with the sum of life cycle-costs per year $\left(\mathrm{C}_{\mathrm{LC}}\right)$ and costs associated with unforeseen events per year $\left(\mathrm{C}_{\mathrm{UE}}\right)$ such as accidents or vandalism. $\mathrm{C}_{\mathrm{LC}}$ and $\mathrm{C}_{\mathrm{UE}}$ are constant throughout the duration of the project. Each cost considered must be presented in its present value (valid in the year of construction of the barrier, year 0). All costs are in $€ / \mathrm{m}^{2}$ (other unit may be used as long as it is coherently used).

$$
\mathrm{C}_{\mathrm{n}}=\mathrm{C}_{\mathrm{P}}+n *\left(\mathrm{C}_{\mathrm{LC}}+\mathrm{C}_{\mathrm{UE}}\right) \quad\left[€ / \mathrm{m}^{2}\right]
$$

\subsection{Preparatory costs}

Preparatory costs $\left(\mathrm{C}_{\mathrm{P}}\right)$ are presented in eq. 3 and are the sum of the cost of terrain works $\left(\mathrm{C}_{\mathrm{TW}}\right)$ due to a barrier, expropriation costs $\left(\mathrm{C}_{\mathrm{Exp}}\right)$ and terrain preparation costs $\left(\mathrm{C}_{\mathrm{TP}}\right)$ all in $€ / \mathrm{m}^{2}$.

$$
\mathrm{C}_{\mathrm{P}}=\mathrm{C}_{\mathrm{TW}}+\mathrm{C}_{\mathrm{Exp}}+\mathrm{C}_{\mathrm{TP}} \quad\left[€ / \mathrm{m}^{2}\right]
$$

The cost of terrain works is associated to those who are only necessary due to the thickness of the barrier. Although this cost is often small (particularly when screen barriers are used) it becomes relevant when the thickness of the barrier increases (earth-mounds and some planted barriers). Its calculation is based on the cost of earth moving $\left(\mathrm{C}_{\mathrm{EM}}\right)$, in $€ / \mathrm{m}^{3}$.

An average height of terrain works $\left(\mathrm{H}_{\mathrm{avg}}\right.$ in $\left.\mathrm{m}\right)$, throughout the barrier thickness $(e$ in $\mathrm{m})$ and length, must also be defined. The cost of terrain works can therefore be determined with eq. 4 $\left(\mathrm{C}_{T W}\right.$ is the cost of terrain works, $€ / \mathrm{m}^{2} ; \mathrm{C}_{\mathrm{EM}}$ the Earth moving cost, $€ / \mathrm{m}^{3}$ and $\mathrm{H}$ the barrier height, $\mathrm{m}$ ).

$$
\mathrm{C}_{\mathrm{TW}}=\left(\mathrm{H}_{\mathrm{avg}} * e^{*} \mathrm{C}_{\mathrm{EM}}\right) / \mathrm{H} \quad\left[€ / \mathrm{m}^{2}\right]
$$

Expropriation costs $\left(\mathrm{C}_{\mathrm{Exp}}\right.$ in $\left[€ / \mathrm{m}^{2}\right)$ are related to the acquisition of land necessary to the construction of the barrier. They are based on the average expropriation cost $\left(\mathrm{C}_{\text {Exp_avg }}\right.$ in $\left.€ / \mathrm{m}^{2}\right)$ throughout the barrier's length, multiplied with the barrier thickness ( $e$ in $\mathrm{m}$ ) and divided by the barrier's height ( $\mathrm{H}$ in $\mathrm{m}$ ), correctly defining the expropriation cost per square meter (5).

$$
\mathrm{C}_{\mathrm{Exp}}=\left(e^{*} \mathrm{C}_{\text {Exp_avg }}\right) / \mathrm{H} \quad\left[€ / \mathrm{m}^{2}\right]
$$

Terrain preparation costs $\left(\mathrm{C}_{\mathrm{TP}}\right.$ in $\left.€ / \mathrm{m}^{2}\right)$ are referred to the construction of foundations, if necessary, for the later construction of the barrier. When accurate information is not available, $\mathrm{C}_{\mathrm{TP}}$ can be defined as a percentage $\left(P_{\mathrm{TP}}\right.$ in $\left.\%\right)$ of the barrier initial cost $\left(\mathrm{C}_{0}\right.$ in $€ / \mathrm{m}^{2}$, see eq. 10), defined in chapter 4.3 (eq. 10). When that situation occurs, terrain preparation costs $\left(\mathrm{C}_{\mathrm{TP}}\right)$ can be calculated with eq. 6 .

$$
\mathrm{C}_{\mathrm{TP}}=\left(P_{\mathrm{TP}} * \mathrm{C}_{0}\right) / \mathrm{H} \quad\left[€ / \mathrm{m}^{2}\right]
$$




\subsection{Life cycle costs}

Life cycle costs $\left(\mathrm{C}_{\mathrm{LC}}\right)$ comprise all operations occurring during the barrier's life cycle such as acquisition or production, transport, construction or assembly, maintenance, and disassembly or demolition, and debris removal. After a barrier reaches the end of its own life cycle before the end of the project's life cycle, a new one begins with the construction of a similar barrier. Life cycle costs per year $\left(\mathrm{C}_{\mathrm{LC}}\right.$ in $\left.€ / \mathrm{m}^{2}\right)$ can be calculated with eq. 7 ( $\mathrm{C}_{\mathrm{I}}$ : Initial life cycle costs per year, $€ / \mathrm{m}^{2} ; \mathrm{C}_{\mathrm{PMO}}$ : Periodic maintenance operations costs per year, $€ / \mathrm{m}^{2} ; \mathrm{C}_{\mathrm{ELC}}$ : End of life cycle costs per year, $€ / \mathrm{m}^{2}$ ).

$$
C_{L C}=C_{I}+\sum_{i=1}^{m} C_{P M O_{i}}+C_{E L C} \quad\left[€ / \mathrm{m}^{2}\right]
$$

Initial life cycle costs $\left(\mathrm{C}_{\mathrm{I}}\right)$ refer to the cost of construction of a barrier (including production or acquisition, transport and assembly) and mark the beginning of its life cycle. The $\sum \mathrm{C}_{\mathrm{PMO} i}$ is the sum of the costs of all proposed maintenance operations $i$ while $\mathrm{C}_{\mathrm{ELC}}$ is associated with disassembly or demolition and debris removal operations.

$\mathrm{C}_{\mathrm{I}}, \mathrm{C}_{\mathrm{PMO} i}$ and $\mathrm{C}_{\mathrm{ELC}}$ can be expressed through the generic eq.s 8 and 9 . They are defined as a cost of an operation $j\left(\mathrm{C}_{j}\right)$. If $\mathrm{V}_{\mathrm{j}}$ is the value of that operation $j$ then it can be defined as a percentage $P$ of the barrier's initial cost while $l$ is the unitary length of the barrier where that operation occurs ( $l$ can also be perceived as the percentage of a barrier's square meter where that operation occurs).

$$
\begin{aligned}
& \mathrm{C}_{\mathrm{j}}=\mathrm{V}_{\mathrm{j}} * l \quad\left[€ / \mathrm{m}^{2}\right] \text {; every } \mathrm{X} \text { years } \\
& \mathrm{V}_{\mathrm{j}}=P * \mathrm{C}_{0}
\end{aligned}
$$

Where, $\mathrm{C}_{j}$ : Cost of a generic operation $j\left[€ / \mathrm{m}^{2}\right] ; \quad \mathrm{V}_{\mathrm{j}}$ : Value of a generic operation $j\left[€ / \mathrm{m}^{2}\right]$;

$P$ : Percentage of $\mathrm{C}_{0}$ that define the cost of a generic operation $j[\%]$;

$l$ : Unitary length of the barrier where a generic operation $j$ occurs [\%];

$\mathrm{C}_{0}$ : Barrier's initial cost $\left[€ / \mathrm{m}^{2}\right] ; \quad \mathrm{X}$ : Periodicity [years].

The initial cost of the barrier $\left(\mathrm{C}_{0}\right.$ in $\left.€ / \mathrm{m}^{2}\right)$ is the sum of production costs $\left(\mathrm{C}_{\text {Prod }}\right.$ in $\left.€ / \mathrm{m}^{2}\right)$, transportation costs $\left(C_{\text {Trans }}\right.$ in $\left.€ / \mathrm{m}^{2}\right)$ and assembly or construction costs $\left(C_{A C}\right.$ in $\left.€ / \mathrm{m}^{2}\right)$, valid for the year of construction of the barrier (year 0), as shown by eq. 10 .

$$
\mathrm{C}_{0}=\mathrm{C}_{\text {Prod }}+\mathrm{C}_{\text {Trans }}+\mathrm{C}_{\mathrm{AC}} \quad\left[€ / \mathrm{m}^{2}\right]
$$

The number of years after which an operation is repeated (periodicity) must be provided. An alternative approach is that of dividing the cost of each operation for the number of years until that operation is repeated (periodicity). This corresponds to a management perspective where, each year, a part of the cost of that operation accounted for.

In both cases the operation that is being paid only occurs at the end of the defined period for it to repeat itself. The main difference between the two approaches is when (in time) costs are accounted for. In the first case costs are accounted in the year the operation takes place. In the alternative approach costs are accounted throughout the period between two consecutive operations.

In the presented model the second approach is used. As a consequence eq. 8 and 9 must be rewritten as eq. 11 . 


$$
\mathrm{C}_{\mathrm{j}}=\left(\mathrm{V}_{\mathrm{j}} * l\right) / \mathrm{X}=\left(P * \mathrm{C}_{0} * l\right) / \mathrm{X} \quad\left[€ / \mathrm{m}^{2}\right]
$$

Applying the referred concept the initial life cycle cost is the initial cost of the barrier divided by the number of years until a new barrier is needed (duration of a barrier's life cycle in years $-\mathrm{X}_{\mathrm{LC}}$ ). According to eq. 11, for that to be true then the percentage of the barriers initial cost $\left(P_{\mathrm{I}}\right)$ and the length of the barrier where this operation occurs $\left(l_{\mathrm{I}}\right)$ must be both $100 \%$. The periodicity of this operation $\left(\mathrm{X}_{\mathrm{I}}\right)$ is the duration of the barrier's life cycle $\left(\mathrm{X}_{\mathrm{LC}}\right)$.

Costs of periodic maintenance operations $\left(\mathrm{C}_{\mathrm{PMO}}\right)$ constitute an exception as they are not considered in the last period before the end of the barrier's life cycle. For example, if a barrier has periodic maintenance operation every 5 years and the duration of its life cycle is 20 years, only the operations after 5,10 and 15 years are to be performed because after 20 years a new barrier will be needed. Therefore the cost of each maintenance operation should not be divided by its periodicity ( 5 years) but by the duration of the barrier's life cycle ( 20 years) divided by the number of maintenance operations that take place during that time (3, in this case).

The annual cost of periodic maintenance operations can be calculated with eq. 12 where $X_{L C}$ and $X_{P M O}$ are, respectively, the duration of the barrier's life cycle and the periodicity of each maintenance operation $\left(X_{\mathrm{LC}} / X_{\mathrm{PMO}}\right.$ is rounded to the unit). It is, however, necessary to know the values of $P_{\mathrm{PMO}}$ and $\mathrm{X}_{\mathrm{PMO}}$ assuming that the affected length of the maintenance operations $\left(l_{\mathrm{PMO}}\right)$ is $100 \%$.

$$
C_{P M O}=\frac{P_{P M O} * C_{0} * l_{P M O}}{X_{L C}} *\left(\frac{X_{L C}}{X_{P M O}}-1\right) \quad\left[€ / \mathrm{m}^{2}\right]
$$

End of life cycle costs $\left(\mathrm{C}_{\mathrm{ELC}}\right)$ are associated with the disassembly or demolition of the barrier and removal of debris at the end of the barrier's life cycle. It is also related to the initial cost of the barrier $\left(\mathrm{C}_{0}\right)$ as it can be defined as a percentage $\left(P_{\mathrm{ELC}}\right)$ of that cost $(10 \%$ by default $)$. As the total length of the barrier is affected by that operation, $l_{\mathrm{ELC}}$ is $100 \%$. The periodicity of this operation $\left(\mathrm{X}_{\mathrm{ELC}}\right)$ is the duration of the barrier's life cycle $\left(\mathrm{X}_{\mathrm{LC}}\right)$ which, in turn, is associated with the durability of the materials that constitute the barrier. The presented values of $l_{\mathrm{PMO}}, P_{\mathrm{ELC}}$ and $l_{\text {ELC }}$ are considered by default and can be changed, if necessary.

\subsection{Costs due to unforeseen events}

Costs due to unforeseen events per year $\left(\mathrm{C}_{\mathrm{UE}}\right.$ in $\left.€ / \mathrm{m}^{2}\right)$ are associated with repair operations due to accidents or vandalism as shown by eq. 13 (where $\mathrm{C}_{\mathrm{MaA}}$ : Costs due to major accidents per year, $€ / \mathrm{m}^{2} ; \mathrm{C}_{\mathrm{MiA}}$ : Costs due to minor accidents per year, $€ / \mathrm{m}^{2} ; \mathrm{C}_{\mathrm{Vd}}$ : Costs due to vandalism per year, $€ / \mathrm{m}^{2} ; \mathrm{C}_{\mathrm{AD}}$ : Costs due to aesthetic defacement per year, $€ / \mathrm{m}^{2}$ ).

$$
\mathrm{C}_{\mathrm{UE}}=\mathrm{C}_{\mathrm{MaA}}+\mathrm{C}_{\mathrm{MiA}}+\mathrm{C}_{\mathrm{Vd}}+\mathrm{C}_{\mathrm{AD}} \quad\left[€ / \mathrm{m}^{2}\right]
$$

Unforeseen events are not independent from the location of the barrier, its accessibility and the type of nearby traffic. Therefore location susceptibility (S) classes are created that take in consideration the probability of occurrence of these events. Three classes were created, ranging from S1 (Low Susceptibility) to S3 (High Susceptibility), increasing in severity. Barriers with a location susceptibility of $S 1$ are those nearby high speed railways, for example, due to the fact that they are generally restricted spaces thus diminishing the probability of occurrence of many of the unforeseen events (vandalism, aesthetic defacement, etc.). Barriers near low speed railways and highways are examples of location susceptibilities of S2 and S3, respectively. 
Cars crashing, trains derailing, trees falling, tornados and similar events are considered major accidents (that physically destroy the barrier) whereas actions that render the barrier only unable to function but not destroyed (such as when the barrier sound absorption or sound insulation capabilities are compromised) are considered vandalism (stolen pieces, stone throwing, etc.). Graffiti (or poster ads) are considered aesthetic defacement. These costs can also be calculated using the generic eq. 11 .

Costs due to major accidents $\left(\mathrm{C}_{\mathrm{MaA}}\right)$ are independent from the type of barrier (material), particularly in the periodicity of such events $\left(\mathrm{X}_{\mathrm{MaA}}\right)$ and the affected length of the barrier $\left(l_{\mathrm{MaA}}\right)$. It can also be defined as a percentage $\left(P_{\mathrm{MaA}}\right)$ of the initial cost of the barrier $\left(\mathrm{C}_{0}\right)$.

Assuming that, in the event of a major accident, all of the affected portions of the barrier are damaged beyond repair then $P_{\mathrm{MaA}}$ is $100 \%$, as the cost of repair is the construction of a new portion of barrier. By default, it is also assumed that a major accident occurs $\left(\mathrm{X}_{\mathrm{MaA}}\right)$ once every 50 years, for barriers with location susceptibility S1, 40 years for barriers with location susceptibility S2 and 20 years for barriers S3 and that $2 \%$ of the barrier $\left(l_{\mathrm{MaA}}\right)$ is affected in all S types.

This kind of operation can be understood as a major repair (or substitution) operation caused by an event that occurs once every $\mathrm{X}$ years, damaging $l \%$ of the barrier or, alternatively caused by several events that damaged $l \%$ of the barrier throughout $\mathrm{X}$ years (at which point repairs will be made).

Costs due to vandalism $\left(\mathrm{C}_{\mathrm{Vd}}\right)$ are defined as those associated with the repairs needed after a vandalism action occurs that render the barrier unable to function. Therefore the cost needed for repairing is that of building a new barrier (or part of it) in that location. As a result $\mathrm{C}_{\mathrm{Vd}}$ can be defined as percentage $\left(P_{\mathrm{Vd}}\right)$ of the initial cost of the barrier equal to $100 \%$. By default, it is also assumed that vandalism actions affect $2 \%$ of the barriers length $\left(l_{\mathrm{Vd}}\right)$ in $\mathrm{X}_{\mathrm{Vd}}$ years. $\mathrm{X}_{\mathrm{Vd}}$ is dependant of the barrier's vulnerability to vandalism (related to the material that it is made of) and the location susceptibility. Therefore $\mathrm{X}_{\mathrm{Vd}}$ must be defined on a case by case basis, using table 1, knowing that the higher the barrier's vulnerability to vandalism the smaller $\mathrm{X}_{\mathrm{VD}}$ will be.

Costs due to aesthetic defacement $\left(\mathrm{C}_{\mathrm{AD}}\right)$ (for instance, graffiti and poster ads) can also be defined as a percentage $P_{\mathrm{AD}}$ of the barrier's initial cost $\left(\mathrm{C}_{0}\right)$ although different barrier types will have different percentages associated with them. It is however assumed that repair operations are conducted when $10 \%$ of the barrier is affected $\left(l_{\mathrm{AD}}\right)$. Different barriers will also have a different vulnerability (V) to the occurrence of repairs due to aesthetic defacement events. As a result three vulnerability classes $\mathrm{V}_{\mathrm{AD}}$ were created (V1 to V3) where class V3 means high vulnerability (table 1). A higher vulnerability class $\mathrm{V}_{\mathrm{AD}}$ to aesthetic defacement events means that the occurrence of repair operations is higher (lower periodicity $\mathrm{X}_{\mathrm{AD}}$ ).

Costs due to minor accidents $\left(\mathrm{C}_{\mathrm{MiA}}\right)$ are defined as a percentage $P_{\mathrm{MiA}}$ of the barrier's initial cost $\left(\mathrm{C}_{0}\right)$ equal to $20 \%$ and occur in a length $\left(l_{\mathrm{MiA}}\right)$ equal to $20 \%$ (default values). Similarly to the costs due to aesthetic defacement, different barriers will also have a different vulnerability to the occurrence of repairs due to minor accidents. Vulnerability classes to minor accidents $\mathrm{V}_{\mathrm{MiA}}$ were also established (table 1).

Although all vulnerabilities (to vandalism $\mathrm{V}_{\mathrm{Vd}}$, aesthetic defacement $\mathrm{V}_{\mathrm{AD}}$ and minor accidents $\mathrm{V}_{\mathrm{MiA}}$ ) are related, a barrier does not need to have the same vulnerability class to all of the events.

In the last three discussed events (vandalism, aesthetic defacement and minor accidents) the location susceptibility is also present. Therefore, periodicity values accounting both the barrier's location susceptibility and the barrier's material vulnerability are presented in table 1.

In tables 2 and 3 examples of material vulnerability $\mathrm{V}$ and susceptibility locations $\mathrm{S}$ are provided. 
Table 1 - Relationship between the barrier material vulnerability $V$ (to vandalism $V_{V d}$, to aesthetic defacement $V_{A D}$ and to minor accidents $V_{M i A}$ ), the barrier's location susceptibility $S$ and the periodicity of the repair operations $X_{V d}, X_{A D}$ and $X_{M i A}$.

\begin{tabular}{|c|c|c|c|c|c|c|c|c|c|}
\hline \multirow{3}{*}{$\begin{array}{l}\text { Vulnerability } \mathrm{V}_{\mathrm{Vd}} \mathrm{V}_{\mathrm{AD}} \mathrm{V}_{\mathrm{MiA}} \\
\text { Susceptibility (S) }\end{array}$} & \multicolumn{3}{|c|}{ Low (V1) } & \multicolumn{3}{|c|}{ Moderate (V2) } & \multicolumn{3}{|c|}{ High (V3) } \\
\hline & \multicolumn{9}{|c|}{ Periodicity (years) } \\
\hline & $X_{V_{d}}$ & $\mathrm{X}_{\mathrm{AD}}$ & $\mathrm{X}_{\mathrm{MiA}}$ & $X_{V d}$ & $\mathrm{X}_{\mathrm{AD}}$ & $\mathrm{X}_{\mathrm{MiA}}$ & $X_{V d}$ & $\mathrm{X}_{\mathrm{AD}}$ & $\mathrm{X}_{\mathrm{MiA}}$ \\
\hline Low & 100 & 10 & 12 & 50 & 5 & 6 & 30 & 3 & 2 \\
\hline Medium (S2) & 80 & 8 & 8 & 40 & 4 & 4 & 20 & 2 & 1 \\
\hline High & 80 & 8 & 4 & 30 & 3 & 2 & 10 & 1 & 1 \\
\hline
\end{tabular}

Table 2 - Examples of materials with different vulnerability classes $V$.

\begin{tabular}{cccc}
\hline Material & \multicolumn{3}{c}{ Vulnerability } \\
\cline { 2 - 4 } & $\mathrm{V}_{\mathrm{Vd}}$ & $\mathrm{V}_{\mathrm{AD}}$ & $\mathrm{V}_{\text {MiA }}$ \\
\hline Brick, Concrete & $\mathrm{V} 2$ & $\mathrm{~V} 3$ & $\mathrm{~V} 2$ \\
Earth & $\mathrm{V} 1$ & $\mathrm{~V} 1$ & $\mathrm{~V} 2$ \\
Metal, Plastic (opaque) & $\mathrm{V} 3$ & $\mathrm{~V} 2$ & $\mathrm{~V} 1$ \\
Stone & $\mathrm{V} 1$ & $\mathrm{~V} 1$ & $\mathrm{~V} 3$ \\
Timber & $\mathrm{V} 3$ & $\mathrm{~V} 2$ & $\mathrm{~V} 2$ \\
Transparent Materials & $\mathrm{V} 3$ & $\mathrm{~V} 3$ & $\mathrm{~V} 3$ \\
Vegetation & $\mathrm{V} 3$ & $\mathrm{~V} 3$ & \\
\hline
\end{tabular}

Table 3 - Examples of various susceptibility (S) locations.

\begin{tabular}{cl}
\hline Susceptibility (S) & \multicolumn{1}{c}{ Example locations } \\
\hline Low (S1) & High Speed Railways, Airports, etc. \\
Medium (S2) & Low Speed Railways, etc. \\
High (S3) & Highways, Industrial Facilities, etc. \\
\hline
\end{tabular}

\section{BENEFITS}

\subsection{Concept}

In this model benefits are defined as tangible or intangible characteristics of a barrier to which a numerical value is attributed. Although theoretically a benefit can be either positive or negative, in this model the benefit's numerical values vary from 0 to 1 with 1 being the highest possible (the best) classification. This means that any benefit either adds to the total benefits of a barrier or it simply doesn't. No characteristics are then considered negative in any way that they would reduce the barrier's total benefit value. The concept of benefit in this model is not exactly the same as the economy engineering's definition.

The total benefit (B) of a barrier is calculated (eq. 14) as the sum of five major partial benefits. Each of them is weighted by a parameter $\mathrm{W}_{i}$ that translates the relative importance of each benefit. The sum of all weights $\mathrm{W}_{i}$ is necessarily 1 . Since the benefits are defined with a numerical value and the costs with a monetary value the latter is much higher in numerical value than the first. As a result, benefits can be multiplied by an arbitrary scale factor $F$. This allows for the BCR results to be presented in a convenient scale ( 0 to 100 for example).

Weights $\mathrm{W}_{i}$ can be altered whenever relevant as long as their sum is 1 . In table $4 \mathrm{Bi}$ are defined and default values for weights $\mathrm{W}_{i}$ are presented.

$$
\mathrm{B}=\left(\mathrm{B}_{\mathrm{NA}} * \mathrm{~W}_{\mathrm{NA}}+\mathrm{B}_{\mathrm{NR}} * \mathrm{~W}_{\mathrm{NR}}+\mathrm{B}_{\mathrm{IL}} * \mathrm{~W}_{\mathrm{IL}}+\mathrm{B}_{\mathrm{VI}} * \mathrm{~W}_{\mathrm{VI}}+\mathrm{B}_{\mathrm{EI}} * \mathrm{~W}_{\mathrm{EI}}\right) * F
$$


Table 4 Weights $W_{i}$ associated with each benefit (default values).

\begin{tabular}{cc}
\hline Benefit & $\mathrm{W}_{\mathrm{i}}$ \\
\hline $\mathrm{B}_{\mathrm{NA}}$ - Benefit associated with noise absorption & 0.25 \\
$\mathrm{~B}_{\mathrm{NR}}$ - Benefit associated with noise reduction & 0.15 \\
$\mathrm{~B}_{\mathrm{IL}}$ - Benefit associated with insertion loss & 0.30 \\
$\mathrm{~B}_{\mathrm{VI}}$ - Benefit associated with visual impact & 0.25 \\
$\mathrm{~B}_{\mathrm{EI}}-$ Benefit associated with environmental impact & 0.05 \\
\hline
\end{tabular}

\subsection{Benefit associated with noise absorption}

The benefit associated with noise absorption $\left(\mathrm{B}_{\mathrm{NA}}\right)$ is based on the single number rating for sound absorption $D L_{\alpha}{ }^{1}$ (and varies from 0 to $20 \mathrm{~dB}$ ). These values are organized in four non equaled intervals. As a result, the $\mathrm{B}_{\mathrm{NA}}$ varies between 0 and 1 , linearly in each of those classes (Table 5).

For each type of barrier, their single number rating for sound absorption $D L_{\alpha}$ must be known (if unknown, the default values presented on table 6 can be used).

Table 5 - Benefit associated with noise absorption $B_{N A}$.

\begin{tabular}{ccc}
\hline Class & $D L_{\alpha}(\mathrm{dB})$ & $\mathrm{B}_{\mathrm{NA}}$ \\
\hline $\mathrm{A} 1$ & {$[0 ; 4[$} & {$[0.00 ; 0.25[$} \\
$\mathrm{A} 2$ & {$[4 ; 8[$} & {$[0.25 ; 0.50[$} \\
$\mathrm{A} 3$ & {$[8 ; 10[$} & {$[0.50 ; 0.75[$} \\
$\mathrm{A} 4$ & {$[10 ; 20]$} & {$[0.75 ; 1.00]$} \\
\hline
\end{tabular}

Table 6 - Common default values of $D L_{\alpha}$.

\begin{tabular}{cccc}
\hline Type of Barrier & $D L_{\alpha}(\mathrm{dB})$ & Type of Barrier & $D L_{\alpha}(\mathrm{dB})$ \\
\hline Brick (plain), Concrete (plain) & 0 & Transparent Material & 0 \\
Brick (porous), Gabion Wall & 2 & Metal (non perforated) & 0 \\
Concrete w/ expanded clay & 13 & Metal (perforated) & 16 \\
Concrete w/ wood fibers & 11 & Earth Mound & 3 \\
Timber (plain) & 0 & Plastic (opaque) & 1 to 5 \\
Timber (absorbent) & 9 & Planted (vegetation) & 0 to 3 \\
\hline
\end{tabular}

\subsection{Benefit associated with noise reduction}

The benefit associated with noise reduction $\left(\mathrm{B}_{\mathrm{NR}}\right)$ is based on the single number rating for airborne sound insulation $D L_{R}{ }^{2}$. This single number has only an inferior limit where $D L_{R}$ must not be smaller than 0 . They are organized in three classes (Table 7).

The noise that reaches the receiver is a function of the airborne sound insulation and the insertion loss of the barrier. Assuming that the maximum insertion loss, controlled by the diffraction of sound at the barrier's top edge, is $15 \mathrm{~dB}$ then airborne sound insulation ratings higher than $25 \mathrm{~dB}$ will not bring any additional reduction to the noise reaching the receiver. As a result, a $B_{N R}$ of 1 is considered for class $B 3$, while the benefit varies linearly from 0 to 0.5 and 0.5 to 1 for classes $\mathrm{B} 1$ and $\mathrm{B} 2$, respectively.

It is also necessary that the values of $D L_{R}$ are known (if unknown, the values on table 8 can be used). 
Table 7 - Benefit associated with noise reduction $B_{N R}$.

\begin{tabular}{ccc}
\hline Class & $D L_{R}(\mathrm{~dB})$ & $\mathrm{B}_{\mathrm{NR}}$ \\
\hline $\mathrm{B} 1$ & {$[0 ; 15[$} & {$[0.0 ; 0.5[$} \\
$\mathrm{B} 2$ & {$[15 ; 24]$} & {$[0.5 ; 1.0[$} \\
$\mathrm{B} 3$ & $>24$ & 1.0 \\
\hline
\end{tabular}

Table 8 - Common default values of $D L_{R}$.

\begin{tabular}{cccc}
\hline Type of barrier & $D L_{R}(\mathrm{~dB})$ & Type of barrier & $D L_{R}(\mathrm{~dB})$ \\
\hline Brick (plain or porous) & 35 & Transparent Material & 30 \\
Concrete (all types) & 40 & Metal (perforated or non & 30 \\
& 30 & perforated) & 40 \\
Timber (plain or absorbent) & 50 & Gabion Wall & 25 \\
Earth Mound & 10 & Plastic (opaque) & \\
Planted (vegetation) & & & \\
\hline
\end{tabular}

\subsection{Benefit associated with insertion loss}

The benefit associated with insertion loss $\left(\mathrm{B}_{\mathrm{IL}}\right)$ is defined as a function of the barrier's predicted insertion loss (IL) (for instance with the method at ${ }^{3}$ ) and the barrier's angle ( $\theta$ ) (eq. 15 where $\mathrm{b}_{\mathrm{IL}}$ : Insertion loss criterion; $\mathrm{W}_{i}$ : Weights; $\mathrm{b}_{\theta}$ : Criterion related to the barrier's angle).

$$
\mathrm{B}_{\mathrm{IL}}=f\left(\mathrm{IL}_{500 \mathrm{~Hz}} ; \theta\right)=\mathrm{b}_{\mathrm{IL}} * \mathrm{~W}_{\mathrm{IL}}+\mathrm{b}_{\theta} * \mathrm{~W}_{\theta}
$$

The $\mathrm{B}_{\mathrm{IL}}$ is a weighted average, using weights $\mathrm{W}_{\mathrm{IL}}$ and $\mathrm{W}_{\theta}$, of the barrier's insertion loss score and the barrier's angle. A $\mathrm{W}_{\mathrm{IL}}$ of $90 \%$ was attributed to the insertion loss characteristics while the remainder $\mathrm{W}_{\theta}$ of $10 \%$ was attributed to the barrier's angle characteristics.

The criterion related to the barrier's angle $\left(b_{\theta}\right)$ is 1 when the barrier's angle with the vertical axis is between 5 and 20 degrees. An angle is positive when the top of the barrier is furthest from the noise sources. When the barrier's angle is comprised between 5 and 20 degrees the reflection of noise on the barrier are angled skywards, avoiding both vehicles and low buildings. Angles higher than 20 degrees are not considered as beneficial because of less space due to angled barrier and may present a feeling of confinement and claustrophobia to the people on the protected side of the barrier.

The insertion loss criterion $\left(b_{\mathrm{IL}}\right)$ evaluates the barrier's noise attenuation (IL), predicted for any given distance from the source to the receiver, although a default position for the receiver is suggested (receiver at $20 \mathrm{~m}$ from the barrier, $2 \mathrm{~m}$ in height). It also quantifies the increase of the barrier's insertion loss due to diffracting-edge modification (D), the reduction of the barrier's insertion loss due to the existence of openings in the barrier $\left(\mathrm{IL}_{\mathrm{EO}}\right)$ and the reduction of the barrier's insertion loss due to distance/height relationship of parallel barriers $\left(\mathrm{IL}_{\mathrm{LH}}\right)$. This parameter refers to the influence of parallel barriers on the barrier's effectiveness. The closer two parallel barriers are built the greater the number of reflections on the second barrier that can get across the first, thus diminishing the barrier's effectiveness.

A maximum limit of $18 \mathrm{~dB}$ is considered for the algebraic sum of the four previously presented parameters, above which no gain is considered. Eq. 16 shows how to calculate the $\mathrm{B}_{\mathrm{IL}}$.

$$
\begin{aligned}
& \mathrm{B}_{\mathrm{IL}}=\min \left[\left(\mathrm{IL}_{500 \mathrm{~Hz}}+\mathrm{D}-\Delta \mathrm{IL}_{\mathrm{EO}}-\Delta \mathrm{IL}_{\mathrm{LH}}\right) / 18 ; 1\right] * \mathrm{~W}_{\mathrm{IL}}+ \\
& +1 * \mathrm{~W}_{\theta} \quad \text { if } 5^{\circ} \leq \theta<20^{\circ} \quad \text { or } \\
& +0 \quad \text { if } \theta<5^{\circ} \vee \theta \geq 20^{\circ}
\end{aligned}
$$


For the calculation of $\mathrm{B}_{\mathrm{IL}}$ it is necessary to know the value of the insertion loss at $500 \mathrm{~Hz}$ $\left(\mathrm{IL}_{500 \mathrm{~Hz}}\right.$ ) (for example predicted by ${ }^{3}$ ). According to ${ }^{4}$ the result obtained for the $500 \mathrm{~Hz}$ frequency band is quite similar (in many usual traffic situations) to the result obtained by an A-weighted analysis. As a result the insertion loss at $500 \mathrm{~Hz}$ is considered representative of the entire spectrum and is expressed in $\mathrm{dB}(\mathrm{A})$.

It is also necessary to account for any gains on the barrier's insertion loss due to diffractingedge modifications (D) in $\mathrm{dB}(\mathrm{A})$. If these elements are not installed then $\mathrm{D}$ is 0 . If a diffractingedge modification is made at the barrier's top edge then a gain of $2 \mathrm{~dB}(\mathrm{~A})$ is considered.

Regarding the reduction of the barrier insertion loss due to the existence of openings in the barrier $\left(\Delta \mathrm{IL}_{\mathrm{EO}}\right)$ its value is presented on table 9 and must be introduced in eq. 16 as positive.

The reduction of the barrier insertion loss due to height/distance relationship of parallel barriers $\left(\Delta \mathrm{IL}_{\mathrm{LH}}\right)$ can be accounted for using table 10 .

The calculation of the $B_{\text {IL }}$, particularly the calculation of the insertion loss (IL) could be made using the insertion loss characterizing parameters $\mathrm{D}_{\mathrm{IL}}$ (using ${ }^{5}$ ) or IL (using ${ }^{6}$ ). Whenever available, these parameters are preferred over IL calculated using a mathematical method.

Table 9 - Insertion loss reduction $\left(\triangle I L_{E O}\right)$ due to openings in the barrier [adapted from ${ }^{7}$ ].

\begin{tabular}{ccccc}
\hline \multirow{2}{*}{$\begin{array}{c}\text { Maximum \% of area } \\
\text { occupied by orifices, } \\
\text { fissures or openings }\end{array}$} & \multicolumn{4}{c}{ Insertion Loss $(\mathrm{IL})$ at $500 \mathrm{~Hz}$ without orifices or fissures } \\
\cline { 2 - 5 } & $10 \mathrm{~dB}^{*}$ & $15 \mathrm{~dB}^{*}$ & $20 \mathrm{~dB}^{*}$ & $25 \mathrm{~dB}^{*}$ \\
\hline 6.00 & 5 & 10 & 14 & 19 \\
3.00 & 4 & 7 & 11 & 16 \\
1.50 & 2 & 5 & 9 & 13 \\
0.80 & 1 & 3 & 6 & 10 \\
0.40 & 1 & 2 & 4 & 8 \\
0.20 & 0 & 1 & 3 & 5 \\
0.10 & 0 & 1 & 1 & 4 \\
0.05 & 0 & 0 & 1 & 2 \\
\hline \multicolumn{4}{c}{}
\end{tabular}

Table 10 - Insertion loss reduction $\left(\Delta I L_{L H}\right)$ due to distance/height relationship of parallel barriers [adapted from ${ }^{8}$ ].

\begin{tabular}{ccl}
\hline $\begin{array}{c}\text { Distance/Height } \\
\text { relationship }\end{array}$ & $\begin{array}{c}\text { Maximum reduction of the barrier's } \\
\text { insertion loss } \Delta \mathrm{L}_{\mathrm{LH}} \text { in } \mathrm{dB}(\mathrm{A})\end{array}$ & \multicolumn{1}{c}{ Recommendations } \\
\hline$<10$ & $\geq 3$ & $\begin{array}{l}\text { Actions to minimize reduction of the barrier's insertion } \\
\text { loss are needed. } \\
\text { Reduction of the barrier's insertion loss may be } \\
\text { imperceptible. Usually no additional actions are needed. } \\
\text { No action required. }\end{array}$ \\
\hline $10 ; 20]$ & $0-3$ & No considerable reduction
\end{tabular}

\subsection{Benefit associated with visual impact}

The benefit associated with visual impact $\left(\mathrm{B}_{\mathrm{VI}}\right)$ accounts for the barrier's aesthetics, the use of materials with lower visual impact (transparent or vegetation), the color of the barrier and the general design of the barrier. The $\mathrm{B}_{\mathrm{VI}}$ is evaluated on both sides of the barrier. For each side it is 
calculated with eq. 17 (where, $\mathrm{b}_{A}$ : Aesthetics criterion (weight $\mathrm{W}_{\mathrm{A}}=0.35$ ); $\mathrm{b}_{V T}$ : Use of vegetation or transparent materials criterion (weight $\mathrm{W}_{\mathrm{VT}}=0.35$ ); $\mathrm{b}_{\mathrm{Col}}$ : Color criterion (weight $\mathrm{W}_{\mathrm{Col}}=0.20$ ); $\mathrm{b}_{\text {Des }}$ : Innovative design criterion (weight $\mathrm{W}_{\text {Des }}=0.10$ ).

$$
\mathrm{B}_{\mathrm{VI}}=\mathrm{b}_{\mathrm{A}} \cdot \mathrm{W}_{\mathrm{A}}+\mathrm{b}_{\mathrm{VT}} \cdot \mathrm{W}_{\mathrm{VT}}+\mathrm{b}_{\mathrm{Col}} \cdot \mathrm{W}_{\mathrm{Col}}+\mathrm{b}_{\text {Des }} \cdot \mathrm{W}_{\text {Des }}
$$

Regarding the aesthetics criterion $\left(b_{A}\right)$ the material considered will be the coating material of a barrier. When it is vegetation the $b_{A}$ is 1 . If it is a transparent material then $b_{A}$ is 0.8 . If it is any other opaque material $b_{\mathrm{A}}$ is 0.5 .

This criterion aims to evaluate the impact of the coating materials used, from a global visual impact perspective, while rewarding the use of vegetation and transparent materials. It is important to distinguish it from the use of vegetation or transparent materials criterion $\left(b_{\mathrm{VT}}\right)$ which evaluates the visual impact of the barrier from the user's perspective on how the barrier hides or allows the visualization of the environment skyline behind the barrier. It applies only when vegetation or transparent materials are used. Depending on the type of environment (urban or non urban) this criterion benefits, respectively, barriers with vegetation, hiding the city skyline from the users, and transparent barriers, allowing the landscaped view of non urban environment (eq. 18 where, $P_{\mathrm{ATrans}}$ : Percentage of area of transparent materials, $\% ; P_{\mathrm{AVeg}}$ : Percentage of area of vegetation, \%; $\mathrm{K}_{\mathrm{VT}}$ : Reduction factor for undesired materials; by default is 0.8 ).

$$
\begin{array}{rlr}
\mathrm{b}_{\mathrm{VT}} & =\min \left(\mathrm{K}_{\mathrm{VT}} * P_{\mathrm{AVeg}}+P_{\mathrm{ATrans}} ; 1\right) & \text { if non urban environment } \\
& =\min \left(\mathrm{K}_{\mathrm{VT}} * P_{\mathrm{ATrans}}+P_{\mathrm{AVeg}} ; 1\right) & \text { if } \quad \text { urban environment }
\end{array}
$$

The color criterion $\left(\mathrm{b}_{\mathrm{Col}}\right)$ assigns a numeric value to the major color range existing on each face. The criterion rewards light color ranges assigning them a value of 1 (white concrete; acrylic sheets, etc.). Medium color ranges (concrete, brick, non painted metals, etc.) constitute a color criterion value of 0.5 and dark color ranges (dark timber and similar paints: deep blue, brown, etc.) constitute a color criterion value of 0.2 .

The design criterion $\left(b_{\text {Des }}\right)$ evaluates the presence of innovative designs not only on shapes but also on textures and is 1 when they are present while being 0 when they are not.

The total benefit associated with visual impact $\left(\mathrm{B}_{\mathrm{VI}}\right)$ is a weighted average of the benefits for each side of the barrier. The side turned to the traffic (TS) is weighted by default with 0.65 while the protected side (turned away from the traffic) (PS) is weighted with 0.35 according to eq.s 19 and 20 (where, $b_{\mathrm{A}}$ : Aesthetics criterion; $b_{\mathrm{VT}}$ : Use of vegetation or transparent materials criterion; $\mathrm{b}_{\mathrm{Col}}$ : Color criterion; $\mathrm{b}_{\text {Des }}$ : Innovative design criterion; TS: Traffic Side, side of the barrier turned to the traffic; PS: Protected Side, side of the barrier turned opposite from TS).

$$
\begin{aligned}
\mathrm{B}_{\mathrm{VI}}= & \mathrm{B}_{\mathrm{VI} T \mathrm{TS}} * 0.65+\mathrm{B}_{\mathrm{VI} \mathrm{PS}} * 0.35 \\
\mathrm{~B}_{\mathrm{VI}}= & 0.65 *\left(\mathrm{~b}_{\mathrm{A}} * 0.35+\mathrm{b}_{\mathrm{VT}} * 0.35+\mathrm{b}_{\mathrm{Col}} * 0.20+\mathrm{B}_{\mathrm{Des}} * 0.10\right)_{\mathrm{TS}}+ \\
& 0.35 *\left(\mathrm{~b}_{\mathrm{A}} * 0.35+\mathrm{b}_{\mathrm{VT}} * 0.35+\mathrm{b}_{\mathrm{Col}} * 0.20+\mathrm{b}_{\mathrm{Des}} * 0.10\right)_{\mathrm{PS}}
\end{aligned}
$$

\subsection{Benefit associated with environmental impact}

The benefit associated with environmental impacts $\left(\mathrm{B}_{\mathrm{EI}}\right)$ is also a function of the materials used although they are evaluated from an environmental impact perspective (sustainability). Numerical values are assigned to this benefit depending on the type of materials used in the 
barrier. If natural materials are used (vegetation or earth) $\mathrm{B}_{\mathrm{EI}}$ is 1 . If recycled materials are used or incorporated in other materials $\mathrm{B}_{\mathrm{EI}}$ is 0.7 . If other common materials (concrete, metals, etc.) are used, is 0.4 . If plastics or other materials derived from petroleum are used, $\mathrm{B}_{\mathrm{EI}}$ is 0.1 .

\section{RESULTS}

After every individual cost has been calculated as well as the total benefit for each solution, it is possible to analyze the BCR of each solution for several possible durations of the project. For each duration ( $n$ years) the model calculates the accumulated costs until that year (including those occurring in that year). The total benefit (B) of each barrier is divided by the accumulated cost until that year $\left(\mathrm{C}_{n}\right)$. The result is a BCR of each barrier for that year $n(\mathrm{~B} / \mathrm{C})_{n}$ (eq. 21$)$.

Assuming that the benefit of a barrier remains constant throughout the project's duration, the longer its duration the smaller are their BCRs throughout that time since the accumulated costs of any barrier are always increasing.

It is important however to know that depending on the duration of the project the best solution may not always be the same. The barrier with the highest BCR for a 20 year duration for example might not have the best BCR for a 40 year duration.

$$
(\mathrm{B} / \mathrm{C})_{\mathrm{n}}=\mathrm{B} / \mathrm{C}_{\mathrm{n}}
$$

\section{CONCLUSIONS}

The presented model comprises separate analysis of costs and benefits for each barrier. Its main purpose consists of applying the method to a number of possible barriers to be constructed especially next to a transportation network and use it as a decision helper. When applying the presented model it is possible to calculate the BCR for each possible solution for a number of years which constitutes the project's life cycle duration. While considering different life cycle's duration for the project it is possible to observe that the solution that provides the highest BCR ratio for one possible duration of the project may not be the same solution that provides the highest BCR ratio for a different duration. Therefore the choice of the best solution is not only tied to how much it costs and to the benefits it can provide but also to the time period it will be in use. This model will help planners to better decide in large money consuming projects.

\section{REFERENCES}

1 EN 1793-1:2008 - Road traffic noise reducing devices - Test method for determining the acoustic performance - Part 1: Intrinsic characteristics of sound absorption.

2 EN 1793-2:2008 - Road traffic noise reducing devices - Test method for determining the acoustic performance - Part 2: Intrinsic characteristics of airborne sound insulation.

3 Barry TM and Reagan JA, FHWA Highway Traffic Noise Prediction Model, FHWA-RD-77-108, (1978).

4 Wilson CE, Noise Control: Measurement, Analysis and Control of Sound and Vibration, Harper \& Row, Inc., New York, (1989).

5 ISO 10847. Acoustics. In-situ determination of insertion loss of outdoor noise barriers of all types.

6 ANSI S12:8 (R2008) - Methods for Determination of Insertion Loss of Outdoor Noise Barriers.

7 EPD, Environmental Protection Department, Guidelines on Design of Noise Barriers, Hong Kong: Transportation Department, Highways Department, Government of the Hong Kong SAR, (2003).

8 FHWA, Highway Noise Barrier Design Handbook, Federal Highway Adm., Washington DC, (2000). 